\title{
ESTRUTURALISMO, DESENVOLVIMENTO E LEGISLAÇÃO COMERCIAL
}

\section{STRUCTURALISM, DEVELOPMENT AND COMMERCIAL LEGISLATION}

\section{FÁBIO DA SILVA VEIGA}

Doutor em Direito Empresarial pela Universidade de Vigo, Espanha. Professor convidado do Mestrado em Advocacia da Universidad Europea de Madrid. Professor convidado da Universidade Lusófona do Porto. Pesquisador no Programa de Doutorado da Universidade de Alcalá de Henares, Madrid. Bolsista DPE da CAPES. Presidente do IBEROJUR - Instituto Iberoamericano de Estudos Jurídicos. E-mail: fabio.da@edu.uah.es

\section{JOÃO OTÁVIO BACCHI GUTINIEKI}

Mestrando em Direito Econômico na Faculdade de Direito da Universidade de São Paulo (FD-USP). Pesquisador do Grupo Público da Fundação Getúlio Vargas. Advogado.

\section{RESUMO}

Pelo presente trabalho apresenta-se a teoria neoestruturalista como uma resposta aos desafios enfrentados pelo Direito na atualidade. Para tanto, busca-se conceituar a maneira segundo a qual aplicar-se-ia esta teoria, bem como demonstrar situações práticas que envolvem diretamente a conjuntura político-econômica em seu contato com o Direito Comercial. Por fim, analisa-se o risco, assim como a plausibilidade do estruturalismo frente aos desafios jurídicos atuais.

PALAVRAS-CHAVE: Desenvolvimento; legislação comercial; neoestruturalismo; proteção de interesses; poder econômico. 


\begin{abstract}
The present paper presents the neo-structuralist theory as a response to the challenges faced by law today. In order to do so, it seeks to conceptualize the way in which this theory would be applied, as well as to demonstrate practical situations that directly involve the political-economic conjuncture in its contact with Commercial Law. Finally, we analyze the risk as well as the plausibility of structuralism in the face of current legal challenges.
\end{abstract}

KEYWORDS: Development; Commercial Legislation; Neo-Structuralism; Protection Of Interests; Economic Power.

\title{
INTRODUÇÃO
}

O Direito ainda é visto como uma área em constante atraso e dissonância. Há a percepção de que as leis e sua interpretação e aplicação pelos tribunais estão muitas vezes distantes da realidade social e dos anseios do povo. Não são raras as vezes em que as decisões judiciais vão de encontro com as necessidades e a vontade de determinada população ou setor da sociedade. As razões passam desde a falta de aggiornamento legislativo e vão até questões que envolvem a falta de percepção social por parte dos aplicadores da lei.

Em meio a este verdadeiro desequilíbrio entre as expectativas e a realidade, urgem ao Direito diversos desafios, o principal deles está em ser visto e enxergar-se como um verdadeiro organizador social, a quem cabe ser um sistema de normas que assegure de maneira ativa a existência digna do homem na sociedade, o reconhecimento de um mínimo elementar de direitos.

Isto nos recorda os primeiros estudos de Teoria do Estado, dos quais as suas lições ensinavam que o homem é um ser gregário, que por evolução e natureza termina sempre por viver em grupo, e que entregou parte de sua liberdade ao Estado em busca de uma vida melhor.

Tal organizador social, o Direito, tem por finalidade assegurar a liberdade de agir dos indivíduos, ao mesmo tempo em que subordina esta liberdade ao interesse 
coletivo, buscando encontrar, segundo Eros Roberto Grau (1981, p.1), um ponto de equilíbrio entre estes dois valores (liberdade e interesse coletivo). Este ponto de equilíbrio tem por finalidade manter as possibilidades de livre desenvolvimento dos indivíduos e de suas vontades, buscando, sincronicamente, garantir a coesão e a proteção da coletividade.

Isto tudo para que as vontades privadas dos indivíduos, de maneira individual ou unidos de maneira associativa, não venham a ferir aos outros membros da sociedade, os quais também têm por garantia o livre desenvolvimento de suas existências. Assim, tal equilíbrio tem por finalidade garantir a todos a dignidade que Ihes é necessária para viverem de maneira plena.

Dentre as ditas "atividades" que podem ser exercidas pelos indivíduos, como maneira de expressão de seus anseios e personalidade, a principal delas é a atividade econômica, que pode expressar-se através da empresa. Empresa que pode ser definida como: a atividade econômica organizada ${ }^{1}$ para a produção ou circulação de bens e de serviços, praticada de maneira profissional por alguém, que é o empresário².

Neste ponto, nos recordamos de que a empresa pode se apresentar, segundo o pensamento de Amartya Sem (1999, p.1-3), como um ambiente de relações entre entitlements, propiciando a produção e a troca destes, legitimando a propriedade. Entitlements são conceituados pelo próprio Sen como um conjunto bens alternativos que uma pessoa tem domínio na sociedade, podendo usar a totalidade de direitos e oportunidades deles advindos (SEN, 1984, p.497). Com estas lentes, vê-se a atividade empresarial como uma constante troca de bens.

Afim de não se entrar em grandes discussões conceituais, em que pese estas serem de grande importância, tomaremos por premissa ser a empresa a maneira pela qual a atividade econômica é majoritariamente desenvolvida, sendo por meio das atividades empresariais que os participantes do mercado se apresentam e desenvolvem suas práticas.

\footnotetext{
1 VERÇOSA, 2014, p. 123: "Não há empresa sem organização, diferenciado-se uma das outras, entre outras circunstâncias, pelo nível e pela dimensão da organização. Microempresários ou pequeno empresários, ou ainda, empresas altamente especializadas em sua atividade atuam em níveis restritos de organização".

2 Definição de "empresário" dada pelo Art. 966 do Código Civil de 2002.
} 
Desta maneira, a empresa tem ligação com o que se considera atividade econômica, vista como um todo, e, por via de consequência, tem também responsabilidades ligadas à questão do desenvolvimento. Isto porque, como se tratará mais adiante, é também por meio da atividade econômica empresarial que se conseguiria chegar a melhores patamares econômicos, sociais e culturais, considerando-se, para tanto, uma sociedade de "livre mercado".

O desafio está, assim, em perceber como e o quanto a empresa é importante para o desenvolvimento, buscando fazer com que estas atividades gerem para além do lucro, sua finalidade precípua aos investidores, mudanças positivas na sociedade que se encontra ao seu redor.

Não se trata aqui, jamais, de "terceirizar" as atividades típicas e de obrigação do Estado, entregando-as para as mãos dos particulares. Mas sim de fazer com que, de maneira simbiótica, possam tais atividades privadas contribuírem de maneira verdadeira para a melhoria nas condições de vida das pessoas que compõem a sociedade.

As próximas páginas deste texto, portanto, serão dedicadas às ideias de cunho estruturalista, ao manejo do direito de maneira com que ele volte a ser protagonista dentro das relações sociais, cumprindo seu papel de organizador social, deixando de ser um mero acatador dos ideais e dos objetivos econômicos individualistas.

\section{LIVRE INICIATIVA, EMPRESA E FUNÇÃO SOCIAL}

A Constituição Federal de 1988 estabelece que a ordem econômica é fundada na livre iniciativa e na valorização do trabalho humano, tendo por finalidade assegurar a todos existência digna, tendo em conta os ditames da justiça social e respeitando uma série de princípios ${ }^{3}$.

Entretanto, a mera prescrição constitucional, em que pese marcante, não nos parece ser suficiente para fazer com que a atividade empresarial proporcione

${ }^{3}$ CF/88, Art. 170, caput. 
desenvolvimento econômico. As bases fundadoras, livre iniciativa e valorização do trabalho humano, são demasiado amplas e indefinidas. Os ditos princípios a serem respeitados, dos quais destacamos a "função social da propriedade" e a "redução das desigualdades sociais e regionais" também parecem carecer de maior certeza e profundidade.

A criação de balizas e definições mais certeiras aos conceitos prescritos no texto constitucional parece ser a primeira etapa necessária para que estes sejam verdadeiramente respeitados. Certamente tais balizas e definições estão ligadas diretamente às escolhas políticas, mas não se pode olvidar que tais escolhas subordinam-se às escolhas do constituinte, que definiu no caput do art. 170 e no art. 3 o da Constituição caminhos e objetivos, dentre os quais tem-se o "desenvolvimento nacional" e a "erradicação da pobreza".

Os fundamentos e princípios da Ordem Econômica, por mais que pareçam indefinidos, estão subordinados diretamente aos objetivos fundamentais da República, com a presença maciça do ideal de desenvolvimento, melhoria da qualidade de vida da população, em síntese, conforme discorre Carlos Portugal Gouvêa, de reduzir as desigualdades ${ }^{4}$.

Modo pelo qual, não se pode interpretar conceitos em contradição a estes objetivos definidos na Constituição, sob pena deles levarem ao "nada jurídico". O desenvolvimento é, claramente, um destes objetivos, senão o principal deles.

Perceba-se que a Constituição nem faz menção exclusiva ao "desenvolvimento econômico", mas coloca a questão como sendo de "desenvolvimento nacional".

Assim, o simples crescimento quantitativo da atividade empresarial e das trocas econômicas, aumento dos parques fabris, podem até aumentar o Produto Interno Bruto (PIB) do país, indicando o crescimento em números, mas que, em última instancia, por vezes, nada representam para o desenvolvimento integral de uma

\footnotetext{
${ }^{4}$ PORTUGAL GOUVEAA, 2013, p. 461: "In the case of the Brazilian constitutional system, there cannot be any doubt that the purpose of the protective system for social and economic rights is reducing inequality. First of all, in the vert preamble of the Federal Constitution of 1988 it is clearly estabilished that one of the primary functions of the Brazilian government involves equality, in the sense of the word defined in the third clause in Article 3, which sets as one of the four fundamental objectives of the Federal Republic of Brazil, 'to eradicate poverty and substandard living conditions and to reduce social and regional inequalitites".
} 
sociedade (NUSDEO, 2002, p.16). O crescimento do PIB per capita, igualmente, pode indicar uma maior concentração de capital, não indica, de maneira direta, que a renda está a ser distribuída, questão que foi tratada em profundidade por Raúl Prebish no que concerne à distribuição de renda na América Latina ${ }^{5}$. Assim, o PIB, sozinho, não pode ser colocado como um índice fiável de desenvolvimento ${ }^{6}$.

Ademais, não basta um desenvolvimento quantitativo, mas sim um desenvolvimento qualitativo, de modo que não se pode confundir "desenvolvimento" com "crescimento". Para Fábio Nusdeo, o desenvolvimento acontece quando o crescimento do PIB "faz-se concomitantemente com profundas alterações em toda a estrutura do país envolvido, por trazer como consequência uma série enorme de modificações de ordem não apenas econômica, mas também cultural, psicológica e social" (NUSDEO, 2002, p.17).

$O$ alcance do desenvolvimento e da justiça social ${ }^{7}$, segundo Modesto Carvalhosa (1972, p.70), não se dá exclusivamente pelo crescimento da produção, mas, por outro lado, é impossível desvincular tal objetivo do aumento e diversificação da produção de bens e serviços. Portanto, no atual patamar econômico mundial, o desenvolvimento se daria de maneira conjunta com o crescimento econômico, crescimento que, do nosso ponto de vista, não se dá apenas de modo baseado em grandezas matemáticas, mas em especial na qualidade e no "valor agregado" que carregam os produtos.

\footnotetext{
${ }^{5}$ Sobre o aumento da renda per capita PREBISCH, 2000, p. 116: "É evidente que o crescimento econômico da América Latina depende do aumento da renda média per capita, que é muito baixa na maioria desses países, e do aumento da população. $\mathrm{O}$ aumento da renda média per capita só poderá ser obtido de duas maneiras. Primeiro, através do aumento da produtividade, e segundo, dada uma determinada produtividade, através do aumento da renda por trabalhador na produção primária, comparada à renda dos países industrializados que importam parte dessa produção. Esse reajuste, como já foi explicado, tende a corrigir a disparidade de renda provocada pela forma como o fruto do progresso técnico é distribuído entre os centros e a periferia".

${ }^{6}$ Neste sentido PIKETTY, 2014, p. 66: "The reality of inequalirty between countries is multidimensional, and it is misleading to say that it can all be summed up with a single index leading to an unanbiguous classification, especially between countries with fairly similar avarage incomes".

7 Segundo GRAU, 1981, p. 56: "O elemento fundamental na noção de justiça social, como fim da ordem econômica, está centralizado na pressuposição de uma melhoria da repartição do produzido como consequência da sua realização".
} 


\subsection{A LIVRE INICIATIVA NA ORDEM CONSTITUCIONAL}

Do título deste capítulo do texto, temos que um dos pontos sobre os quais nos comprometemos a enfrentar é o da "livre iniciativa". O conceito de liberdade de iniciativa pode ser compreendido como o de um direito, um direito que pode ser exercido pelos cidadãos em iniciarem uma atividade empresarial, consoante à ordem econômica, sem amarras ou barreiras à entrada.

Tal "direito" de exercer atividades privadas é praticamente única saída para o domínio das atividades econômicas, vez que o Estado tem competência residual para a prática de atividades econômicas, ou seja, estas devem ser praticadas por privados, salvo exceções, nos termos do art. 173 da Constituição.

Nas palavras de Modesto Carvalhosa (1972, p.116): "conceitua-se, portanto, a iniciativa econômica privada como direito subjetivo dos residentes de, preferencialmente, organizarem e exercitarem qualquer meio de atividade econômica voltada à obtenção de um rendimento de capital".

Porém, não estamos diante de um direito absoluto. A livre iniciativa, por mais que seja a base fundamental de toda a ordem econômica, tem por freio a valorização do trabalho humano, e também passa por restrições. Eros Roberto Grau (1981, p.83) escreveu que "(...) o princípio é consagrado não em termos absolutos, mas apenas relativos. O jogo da concorrência econômica é ordenado pelo Estado e passa ele também papel ativo como conformador do processo econômico".

A livre iniciativa, para além de um direito, é um "instituto"8 que baseia a ordem econômica constitucional, passível de restrições e destinado à atividade de objetivos, entre eles a justiça social e o desenvolvimento nacional. Tal delimitação molda a liberdade de prática de atividades econômicas de modo a garantir outros objetivos, já citados anteriormente, respeitando os princípios elencados em toda a Constituição e na ordem jurídica como um todo, vez que, como sempre explicita Eros Roberto Grau (2009), o direito não se interpreta em tiras, mas como um todo.

Assim, podemos perceber e concluir parcialmente que, a livre iniciativa, enquanto fundação mestra da ordem econômica, não é um direito de liberdade

\footnotetext{
${ }^{8}$ Segundo VERÇOSA, 2014, p. 116, instituto seria um objeto de direito delimitado em seus elementos pela lei ou pela doutrina.
} 
absoluto, mas antes um instituto permeado de restrições e de objetivos. Não se pode, portanto, interpretar a livre iniciativa como sendo uma abertura permanente e indefinida, mas sim uma liberdade dada aos cidadãos para ser exercida com responsabilidade, pautada na própria Constituição e na lei.

\subsection{A FUNÇÃO SOCIAL DA PROPRIEDADE (E DA EMPRESA)}

Continuando a trabalhar questões pertinentes ao Art. 170 da Constituição, temos, dentre os ditos princípios que orbitam ao redor da atividade empresarial, o princípio da "função social da propriedade". Um primeiro pensamento sobre a definição de "função social da propriedade", certamente, confirma as dúvidas que antes levantamos sobre os perigos da sua indefinição sustentada pelos princípios.

Isto porque, já na década passada, com a presença deste mandamento na Constituição de Weimar ("a propriedade obriga"), diversas eram as discussões sobre como aplicar a função social da propriedade, se esta se restringia à propriedade de bens de raiz, como a propriedade imobiliária, ou se sujeitaria também a propriedade mobiliária e, destaque-se, os meios de produção.

Parece-nos, que seria até ingênuo pensar que, mesmo disposto no artigo da Constituição que trata sobre a ordem econômica, como um princípio a ser seguido, este não se aplicaria aos meios de produção. Mesmo antes da vigência do atual texto constitucional, vez que a função social da propriedade não debuta na Constituição de 1988, Fábio Konder Comparato (1986, p.71-79) já havia escrito sobre o assunto, em um artigo denominado "Função social da propriedade dos bens de produção".

Porém, para nós, a questão principal estaria em saber até que ponto a "função social da propriedade" aplicada à atividade empresarial, transformando-se em "função social da empresa", resolvem dúvidas e orientam a atividade empresarial rumo ao desenvolvimento.

Isto porque, como já antes tratado, o excesso de princípios que orbitam sobre determinadas situações jurídicas, como é o caso da atividade empresarial, terminam por resultar algo que, na prática, nada tem de positivo, não agrega valor, não gera nenhuma mudança. Peca-se pelo excesso. Princípios tidos por importantes para a interpretação dos contratos e das relações jurídicas, como o da função social da 
propriedade, são de difícil definição. O que esperar da empresa com a aplicação sobre as atividades desenvolvidas por ela do princípio da função social da propriedade?

Como o próprio Fábio Konder Comparato (1996, p.38-46) expôs em um texto posterior, a atividade empresarial é cada vez mais descentralizada, chamada pelo autor de "terceirizada", isto é, dá-se por meio das redes contratuais que interrelacionam diversas empresas. Como exigir uma "atuação social direta" de uma empresa quando, na realidade atual, o interesse dela está todo voltado para a geração de lucros?

É difícil imaginar o feitio de exigências para as empresas com fundamento na função social da propriedade. Até porque, tais exigências, na maioria dos casos, envolvem atividades que são, na realidade, função e obrigação do Estado. Estado que não pode furtar-se de cumprir com os seus deveres simplesmente pela presença de um princípio constitucional que exige que a propriedade privada, e, no caso em questão, a empresa, cumpra uma função social.

Estas são dificuldades que levantamos aqui não são para dizer que não há saída alguma. Mas antes para ressaltar a necessidade de mudanças que vão para muito além do endeusamento dos princípios, que parecem virar uma verdadeira caixa de soluções para tudo.

Os princípios, claramente, têm grande importância integrativa e interpretativa dentro do sistema jurídico, mas, sozinhos, não conseguem solucionar toda a miríade de problemas atuais, muito menos a questão do desenvolvimento. Pode-se até acreditar que eles têm a capacidade de solucionar todos os conflitos, mas quem nisto crê, não percebe que, no fundo, estar-se-ão tomando medidas arbitrárias, deficitárias de legitimação democrática.

Isto porque, esta será uma decisão a ser tomada por alguma autoridade que, se não for o Poder Legislativo, poderá ultrapassar sua competência e legitimidade, usurpando as funções daquele, criando decisões arbitrárias e fora dos ditames constitucionais. Assim, o próprio Fábio Konder Comparato termina por declarar a inutilidade do princípio da função social da empresa, quando visto de maneira solitária e considerando o atual modo de organização empresarial (COMPARATO, 1996, P.45$46)$. 
Disto, temos a necessidade da lei interpretativa para a consecução dos próprios princípios garantidos na Constituição. A mudança nas estruturas, que será tratada no próximo capítulo deste texto, busca solucionar incertezas e direcionar, de maneira clara, que a atividade empresarial tenha impacto jurídico real sobre o desenvolvimento.

\section{MUDANÇAS RUMO AO DESENVOLVIMENTO}

Como tratado brevemente no último capítulo, o direcionamento das atividades empresariais para o desenvolvimento, pode dar-se por mudanças de caráter estrutural. Tal visão estruturalista busca recolocar o direito em seu papel de organizador social, vez que a ciência jurídica, na atualidade, parece ter passado a um papel de conformador da atividade econômica, tendo a finalidade de reduzir os chamados "custos de transação" (COASE, 1937, p.386-405) para a maximização da eficiência (lucro), assunto de enfoque do movimento law and economics, chamado no Brasil de "análise econômica do direito" (SALOMÃO FILHO, 2013, p.52-53).

Não se trata aqui de fazer com que as empresas tenham por motte "o desenvolvimento do Brasil", o que é barroco. Até porque, no mundo real, as decisões corporativas são tomadas tendo em conta os custos e os benefícios, um cálculo aritmético para o qual pouco importa se está ou não impulsionando o desenvolvimento de determinada nação, conforme retrata José Eduardo Faria9 .

Portanto, aqui, a questão é fazer com que o direito tenha um papel de protagonismo, de responsável pela organização social, papel que hoje encontra-se nas mãos dos detentores do poder econômico. Assim, por esta saída, conseguir-seia fazer com que a regulamentação e regulação da atividade empresarial gerasse efeitos diretos sobre o desenvolvimento econômico do país.

\footnotetext{
9 Sobre esta questão FARIA, 1997, p. 47, expõe: "Sem ter como ampliar a complexidade de seu ordenamento jurídico e de seu aparato judicial em nível equivalente de complexidade e diferenciação funcional dos diferentes sistemas sócioeconômicos, eles passam a agir pragmaticamente. Afinal, se quanto mais tentam disciplinar e intervir, menos conseguem ser eficazes, obter resultados satisfatórios, manter a coerência lógica e assegurar a organicidade de seu direito positivo, não Ihes resta outro caminho para preservar sua autoridade funcional: quanto menos procurarem disciplinar e intervir, menor será o risco de acabarem desmoralizados pela inefetividade de seu instrumental regulatório e de seus mecanismos de controle".
} 
Tudo sem esperar qualquer "benevolência" por parte do mercado, mas criando normas e fortalecendo as instituições que irão aplicá-las, de maneira a moldar as atividades econômicas e suas consequências, fazendo com que estas tenham efeitos e mudanças positivas sobre questão que vai além da mera divisão de lucro.

Com tais mudanças estruturais, segundo Calixto Salomão Filho, o direito deixa de ter uma atividade de lógica meramente compensatória, de reparar danos post factum e passa a utilizar-se de soluções includentes, visando proteger os interesses daqueles que são afetados pela atividade empresarial e que, na maioria das vezes, não são sócios nem acionistas do negócio.

A regulamentação da atividade empresarial, parte, então, de ideias de acesso e inclusão. Tendo em consideração que as ditas regras compensatórias, apesar de importantes, não são suficientes e terminam por manter o estado atual das coisas. Pois existem desequilíbrios contínuos que não podem ser continuamente recompensados, criando uma verdadeira cifra negra, de atividades que prejudicam a comunidade, mas não a recompensam, entrando tal cifra negra também para a contabilidade de lucros.

Estes desequilíbrios contínuos terminam por gerar desproteção aos que, de uma maneira ou outra, sofrem efeitos de atividades empresarias. Meio ambiente, trabalho, pobreza e urbanização são questões afetadas pelos ditos desequilíbrios. Como dito, tais indenizações entram para a conta dos custos da atividade, em especial nas grandes empresas, sendo repassadas aos consumidos finais (prejudicados), ao ponto de que a infração à lei e o pagamento de multas e reparações compense, mantendo a lucratividade.

Desta maneira, ao fazer uma radiografia da situação da legislação brasileira, podemos chegar à conclusão, sem maiores empirismos, que algo está a falhar. Se por um lado temos uma imensidão de princípios postos, do outro temos a dificuldade e os perigos na conceituação e aplicação destes princípios, ainda a tendência à manutenção do estado da arte.

Isto porque, como escrevemos logo no início, o direito afastou-se dos problemas sociais, e, segundo Calixto Salomão Filho, tal afastamento se deu por conta do próprio positivismo, racional e intimista, que fizeram com que o direito perdesse a capacidade de considerar os interesses sociais, perdendo a capacidade 
de organizador, subordinando a solução dos grandes problemas da sociedade a outras ciências (como a ciência econômica) (SALOMÃO FILHO, 2012, p.533-547).

Neste ponto, uma pergunta vem à mente: qual o caminho a seguir? Grandes mudanças?

Segundo os estudos de Calixto Salomão Filho, para a aplicação das reformas de caráter estrutural não são necessárias mudanças em todo o sistema. São mudanças estruturais por levarem em conta a estrutura econômica e social, conhecimentos interdisciplinares que foram deixados de lado pelas codificações e pelo positivismo. Temos que a ter a ideia de que, o direito, por si só, não se basta.

Desta maneira, os câmbios estruturais estariam ligados a um direito que bem percebesse o funcionamento das estruturas, a divisão e a concentração do poder, para assim poder verificar quais são os interesses envolvidos em determinada atividade para, a partir deste "termômetro dos interesses" poderem ser feitas declarações que os considerem.

Tais declarações de interesses oferecem balizas, guias de interpretação para a interpretação da lei e dos princípios inerentes à determinada questão. A questão, portanto, não é apenas de conteúdo material das normas, mas de organizar e reger as relações em sociedade (SALOMÃO FILHO, 2012, p.533-547). Passe-se a considerar os interesses divergentes, e não apenas a mera aplicação da letra da lei de maneira ordinária, dogmática e intimista, mantendo o status quo.

Assim, para se ter o desenvolvimento como consequência da atividade empresarial, pela utilização de uma lente estruturalista, os ajustes vão para além da regulamentação dos princípios, como nos primeiros capítulos defendíamos, por conta da falta de certeza causada pela abertura destes. Para Calixto Salomão Filho (2014, p.47), é necessário que tal regulamentação se disponha a intervir na organização empresarial, estabelecendo quais são os interesses a serem considerados.

Portanto, a legislação empresarial deve ter capacidade de intervir nas estruturas econômicas de maneira a criar inclusão e oportunidade de escolha para os indivíduos, e as declarações de interesses, como tratamos anteriormente, servirão de guias para o aplicador da lei, que deve ter noção exata de quem são os afetados pela ação a ser tomada, e quais os interesses devem ser levados em conta. 
O desafio, mora, entretanto, em conseguir lograr tais efeitos em tempos de um direito e economia globais, que levam em consideração cada custo envolvido na operação para a tomada de decisões empresariais. Levando em conta, ainda, que os "custos sociais" entram nesta conta, conforme tratado novamente pelo Professor José Eduardo Faria (2007, p.21), em entrevista à revista Getúlio.

\section{O NÃO-SINCRONISMO EM SITUAÇÕES REAIS}

Há alguns casos em que, utilizando as lentes do estruturalismo jurídico, o nãosincronismo entre as normas jurídicas e a conjuntura brasileira se mostra na prática. O retorno ao tempo dos códigos é um deles.

Assim, primeiramente trataremos de um caso de lege ferenda, referindo à ideia de um novo Código Comercial para o Brasil, em momentos que a "salvação temporária" do direito positivo está na criação de normas esparsas e leis específicas, com a criação de microssistemas complexos e especializados, que contemplem interesses e soluções específicos ${ }^{10}$.

Outra questão a ser tratada está nas críticas tecidas por Calixto Salomão Filho à realidade da legislação antitruste brasileira, tratada no segundo e último tópico. Tendo esta como uma legislação totalmente importada de outra conjuntura econômica, baseada em interesses que estariam distantes dos que deveriam ser tutelados pelo antitruste em um país com o histórico socioeconômico como o do Brasil.

\subsection{O PROJETO DE NOVO CÓDIGO COMERCIAL: VELHAS NOVIDADES?}

A proposta de um novo Código Comercial para o Brasil, representada pelo Projeto de Lei (PL) no 1572/2011, da Câmara dos Deputados, tem, seus oito primeiros artigos, formando um título ao qual foi dado o nome de "Dos Princípios do direito da empresa". Considerando que nestes primeiros artigos estão a base principiológica para toda a aplicação de todo o código, será neste título que iremos dar foco.

${ }^{10}$ Cf. retrata FARIA, 1997, p. 48, quando trata do ordenamento jurídico após a década de 80, "sem centralidade ou exclusividade". 
Mas, primordialmente, cabe uma crítica ao "positivismo dos códigos", à codificação, que termina por gerar uma legislação hermética, de difícil modificação, indo em contramão as próprias características do direito comercial, como o dinamismo e o fragmentarismo. O dinamismo das relações comerciais exigem constantes mudanças legislativas, em virtude, inclusive, das próprias mudanças tecnológicas.

Disto, criar um novo Código Comercial é, além de desnecessário, prejudicial para uma aplicação do direito como organizador social ${ }^{11}$.

O PL do Código Comercial, além de repetir, em seu artigo 4º , princípios presentes no artigo 170 da Constituição, termina-se por estranhamente esquecer da "valorização do trabalho humano", que também é base fundante da ordem econômica, reforça-se a "liberdade de iniciativa".

Tamanho é o reforço da "liberdade de iniciativa" que o artigo $5^{\circ}$ do projeto de lei traz o "reconhecimento" de questões decorrentes daquele primeiro princípio. Busca-se, neste artigo, reconhecer, entre outros, o seguinte: da imprescindibilidade da empresa privada, do lucro como principal fator de motivação da iniciativa privada e da importância da proteção jurídica do investimento privado.

O balanceamento disto tudo é feito com o já citado princípio da "função social da empresa". $O$ artigo $7^{\circ}$ do projeto explicita, de maneira genérica, como seria cumprida a dita função social ${ }^{12}$. Nada trazendo de novidades, deixando cláusulas abertas, como a questão do desenvolvimento econômico, social e cultural poder ser "da comunidade", "da região" ou, ressalte-se o uso da conjunção "ou", "do país".

Parece, a uma primeira vista, da leitura do artigo $7^{\circ}$, que a função social se cumpre simplesmente pelo respeito ao mínimo de legislação, remetendo mais ao conceito de crescimento econômico que de desenvolvimento por si só. Além do mais, a utilização da conjunção "ou" sobre a localização dos efeitos do desenvolvimento, faz-se perceber que é possível o prejuízo de determinada comunidade em benefício

\footnotetext{
11 Conforme SALOMÃO FILHO, 2014, p. 49: "Exatamente para fugir ao intimismo supra criticado não se pode cair na armadilha dos códigos, que em meio à miríade de artigos, escondem um sistema que visa garantir a permanência das estruturas existentes, sob as mais diversas justificativas (econômicas, sempre) possíveis, desde a garantia da segurança jurídica, até o incentivo à eficiência da atuação empresarial".

12 Art. $7^{\circ}$ : "A empresa cumpre sua função social ao gerar empregos, tributos e riqueza, ao contribuir para o desenvolvimento econômico, social e cultural da comunidade em que atua, de sua região ou do país, ao adotar práticas empresariais sustentáveis visando à proteção do meio ambiente e ao respeitar os direitos dos consumidores, desde que com estrita obediência às leis a que se encontra sujeita".
} 
de uma maioria, retornando aos ideais utilitaristas, refutado pelo próprio espírito de igualdade material presente na Constituição de 1988.

Por último, o artigo $8^{\circ}$ do projeto de lei revela o intimismo e o hermetismo do eventual Código Comercial, dispondo expressamente o seguinte: "Nenhum princípio, expresso ou implícito, pode ser invocado para afastar a aplicação de qualquer disposição deste Código ou da lei".

O projeto de Código fecha-se em si mesmo, impedindo que outros princípios ou balizas de interpretação surjam, muito menos que se utilize de legislação de outras áreas nas atividades empresariais. É como se o artigo dissesse que o Código basta por si só e se fecha em um espaço próprio.

Destas breves visões, e da interpretação literal do que está escrito no projeto de lei, temos que o projeto de novo Código Comercial não traz inovações quanto à evolução da legislação empresarial vista por lentes estruturalistas. O projeto parece estar preocupado somente com a manutenção do poder econômico.

Pouco interessa, no projeto, os interesses da comunidade e daqueles hipossuficientes que sofrem influência direta da atividade de uma empresa. Desta maneira, com a aprovação de uma legislação com este conteúdo, teremos uma regulamentação pro forma ${ }^{13}$, típica das respostas dadas pelo juristas no últimos tempos, após o direito ser relegado ao segundo escalão na responsabilidade pela organização da sociedade.

\subsection{A PARALISIA DO ANTITRUSTE}

Como retratado na chamada deste capítulo, o último sub-tópico será dedicado às críticas proferidas em face do direito da concorrência.

O direito da concorrência, conhecido correntemente também por direito antitruste, pode ser considerado como uma matéria ainda em desenvolvimento no ordenamento jurídico brasileiro. A edição da Lei 12.529, no ano de 2011, reafirmou o regramento do Sistema Brasileiro de Defesa da Concorrência (SDBC), trazendo

\footnotetext{
13 Um exemplo a ser considerado seria o do Novo Código de Processo Civil, que apesar de dois anos de vigência, pouco mudou a realidade e as dificuldades sofridas por toda a sociedade em razão das mazelas do Poder Judiciário. A promessa de um código moderno, tem por realidade uma legislação que, na prática, parece um "mais do mesmo", a diferença é que com os prazos contados em dias úteis.
} 
inovações na estrutura e no procedimento de apuração de ilícitos concorrenciais no país, favorecendo, ainda, atividades envolvendo a "advocacia da concorrência".

Entretanto, percebe-se, na vida quotidiana, um verdadeiro distanciamento entre a sociedade brasileira e a execução, o enforcement, do antitruste. Notícias sobre - Conselho Administrativo de Defesa Econômica (CADE), a autoridade da concorrência brasileira, principal responsável por zelar pelo cumprimento da Lei 12.529/2011, na maioria das vezes relatam a notificação de concentrações ou a assinatura de acordos de colaboração premiada envolvendo grandes corporações.

A sensação de distância entre a realidade social brasileira, o povo, e o direito da concorrência, faz com que alguns estudiosos, como Calixto Salomão Filho, questionem a efetividade e a originalidade do regramento da concorrência no país. Ainda no ano de 2009, em um texto intitulado por "A paralisia do antitruste" (SALOMÃO FILHO, 2009), o referido professor registra questionamentos sobre a efetividade na aplicação de um direito da concorrência baseado na "teoria neoclássica da eficiência".

Em um primeiro momento, o autor questiona a própria possibilidade de se teorizar o comportamento econômico, em razão da diversidade de fatores e de indivíduos envolvidos em cada operação, cada qual com diferentes parcelas, assimétricas e díspares de informação. Para tanto, busca fundamentação nas teorias modernas de Akerloff, Stiglitz e Spence, que descrevem a "teoria do conhecimento" e "economia da informação".

Desta maneira, a detenção de informação é instrumento de poder econômico que não poderia ser olvidado no momento da análise de estruturas e condutas perante as regras no direito da concorrência, para além de impossibilitar a teorização do mercado e da economia como feito pelos neoclássicos.

O segundo ponto trazido pelo autor, sobre a conjuntura brasileira, inclui a necessidade de que as normas e teorias a serem utilizadas levem em consideração recente passado colonial do país, bem como a contínua existência de monopólios, que sucederam ao colonial.

Assim, a importação de normas do antitruste americano, pós-Chicago, e a aplicabilidade destas em uma conjuntura totalmente diferente de onde estas foram criadas, como é o caso da brasileira, geraria ineficiência e mesmo falta de utilidade 
para o direito da concorrência. Assim, a dita "explosão" ou "revolução do antitruste" ocorrida nos países subdesenvolvidos após o "Consenso de Washington" (WAKED, 2016, p.195), serviria para uma simples conformação com a teoria neoclássica da eficiência e abertura de mercados, com a mesma leitura sobre a questão da concorrência ${ }^{14}$.

Em uma discussão envolvendo os objetivos do antitruste, entram em questão quais são os valores sociais a serem protegidos por este regramento quando se parte da premissa de que, apenas o critério da eficiência econômica não é suficiente para garantir condições para o desenvolvimento econômico-social das nações do "terceiro mundo".

Bem como, a preocupação está em saber qual a real eficiência do antitruste cerca de duas década após o seu "nascimento" no mundo subdesenvolvido ${ }^{15}$, considerando as estruturas de poder local e o sistema econômico dos países, a fim de perceber quais vantagens teriam sido efetivamente conseguidas à livre concorrência, ou se a política antitruste não era uma mera forma velada de intervencionismo governamental com a finalidade maior de manter o status quo daqueles que possuem historicamente em suas mãos o poder econômico.

\section{CONCLUSÃO}

A Constituição de 1988, nas normas conhecidas como de "constituição econômica", vale dizer, no capítulo da "Ordem Econômica", trouxe garantias e responsabilidades para o exercício da atividade econômica. Garante o acesso da iniciativa privada ao mercado, mas, concomitantemente, visa garantir dignidade aos trabalhadores e a observância de uma série de princípios, como a função social da propriedade, a defesa do meio ambiente e a redução das desigualdades regionais. Isto conjugado com os objetivos da República presentes no art. 3ํ da mesma Constituição.

\footnotetext{
${ }^{14}$ Sobre o "Consenso de Washington": WILLIAMSON, 1990.

${ }^{15}$ Neste sentido: DE LEON, 2008.
} 
Entretanto, pudemos perceber que isto não é suficiente para garantir que as atividades econômicas empresariais levem ao desenvolvimento integral. Especialmente em face da globalização econômica, que faz com que as grandes corporações pratiquem um verdadeiro law shopping, forçando nações a flexibilizarem ou extinguirem direitos consagrados em seus ordenamentos jurídicos em troca de participação no giro econômico global e saída da pobreza.

Assim, considera-se neste trabalho, como sendo um possível caminho a ser percorrido para a mudança social ver o direito como verdadeiro "organizador social", com uma regulamentação que intervenha na atividade empresarial e explicite os interesses envolvidos, dando ao cidadão maior igualdade e oportunidades. Fazendo com que este deixe de ser o mero complacente do poder econômico para ser um papel fundamental na organização da sociedade, diluindo as estruturas de poder concentrado.

Esta saída, em nossa opinião, se mostra como um desafio aos juristas, vez que os desafios não são resolvidos pela simples evidenciação e proteção de interesses. As forças econômicas, em busca dos rendimentos lucrativos, possuem força suficiente para, caso queiram, tentarem boicotar este tipo de ordenamento complexo e descentralizado.

A certeza do sucesso, ou do fracasso, entretanto, só é sabida por meio da prática. Assim, academicamente, a discussão estruturalista se mostra pertinente e totalmente plausível de ser levada ao campo da prática.

\section{REFERÊNCIAS}

CARVALHOSA, Modesto. Ordem Econômica na Constituição de 1969. São Paulo: Revista dos Tribunais, 1972.

COASE, Ronald. The Nature of the Firm. Economica, New Series, Vol. 4, No. 16, 1937, p. 386-405.

COMPARATO, Fábio Konder. Estado, Empresa e Função Social. Revista dos Tribunais, v. 732, 1996, p. 38-46.

Função social da propriedade dos bens de produção. Revista de Direito Mercantil (RDM), № 63, 1986, p. 71-79. 
DE LEON, Ignacio. Latin American Competition Policy: From Nirvana Antitrust Policy To Reality-Based Institutional Competition Building. 83 Chi.-Kent. L. Rev. 39 (2008).

FARIA, José Eduardo. Direitos humanos e globalização econômica: notas para uma discussão. Estudos avançados, ํo 11 (30), 1997.

$16-23$.

. Globalização é um problema, não um destino. Getúlio, № 2, ano 1, 2007, p.

GRAU, Eros Roberto. Elementos de Direito Econômico. São Paulo: Revista dos Tribunais, 1981.

Ensaio e discurso sobre a interpretação/aplicação do direito. $5^{\text {a }}$ edição. São Paulo: Malheiros, 2009.

NUSDEO, Fábio. Desenvolvimento Econômico - Um retrospecto e algumas perspectivas. In: SALOMÃO FILHO, Calixto (Coord.). Regulação e Desenvolvimento. São Paulo: Malheiros, 2002.

PIKETTY, Thomas. Capital in the Twenty-First Century. Cambridge: Harvard University, 2014.

PORTUGAL GOUVÊA, Carlos. Social Rights Against the Poor. Vienna Journal on International Constitutional Law, v. 7, n. 4, 2013, p. 454-475.

PREBISH, Raúl. O desenvolvimento econômico da América Latina e alguns de seus principais problemas. In: BIELSTHOWSKY, Ricardo (Org.). Cinquenta anos de pensamento na Cepal, v. 1, Rio de Janeiro: 2000, p. 69-136.

SALOMÃO FILHO, Calixto. A paralisia do antitruste. In: Estudos de direito econômico e economia da concorrência: estudos em homenagem ao Prof. Fábio Nusdeo. Curitiba: Juruá; 2009.

Direito Concorrencial. São Paulo: Malheiros, 2013.

Novo Estruturalismo Jurídico: uma alternativa para o direito? Revista Dos Tribunais, Vol. 926/2012, p. 533 - 547, Dez/2012.

. Regulamentação da atividade empresarial para o desenvolvimento. Revista de Estudios Brasileños, v. 1, n. 1, 2014.

SEN, Amartya. Poverty and Famines: An Essay on Entitlement and Deprivation. Oxford: Oxford University, 1999.

497.

Resources, Values and Development. Oxford: Basil Blackwell, 1984, p. 
VERÇOSA, Haroldo Malheiros Duclerc. Direito Comercial: Teoria Geral. 4ª ed. São Paulo: Revista dos Tribunais, 2014.

VEIGA, Fábio da Silva; SILVA, Érica Guerra. Empresa e Direitos Humanos: Da Governança Corporativa à Responsabilidade Social, in: Revista Jurídica LusoBrasileira, Vol. 2, Ano 4, p. 603-631, 2016.

WAKED, Dina. Adoption Of Antitrust Laws In Developing Countries: Reasons And Challenges. Journal of Law, Economics and Policy, Vol. 12, No. 2, 2016.

WILLIAMSON, John (Ed.). Latin American Adjustment. How Much Has Happened? Washington, D.C.: Institute for International Economics, 1990. 